\title{
The lymphocyte/monocyte ratio and red blood cell transfusion during radical retropubic prostatectomy
}

\author{
Jun-Young Park ${ }^{1}$. Jihion $\mathrm{Yu}^{1} \cdot$ Bumjin Lim ${ }^{2} \cdot$ Jiwoong Lee $^{1} \cdot$ Jai-Hyun Hwang $^{1} \cdot$ Yongsoo Lee $^{3} \cdot$ Young-Kug Kim ${ }^{1}$
}

Received: 18 August 2021 / Accepted: 29 September 2021 / Published online: 8 October 2021

(c) Japanese Society of Anesthesiologists 2021

\begin{abstract}
Purpose Despite improvements of strategy in radical retropubic prostatectomy, blood loss is still a major concern. The lymphocyte/monocyte (LM) ratio is a prognostic indicator for various diseases. We identified the risk factors, including the LM ratio, for red blood cell (RBC) transfusion during radical retropubic prostatectomy.

Methods This retrospective study assessed patients who underwent radical retropubic prostatectomy between March 2009 and December 2020. To determine the risk factors for RBC transfusion, a multivariate logistic regression analysis was conducted. A receiver operating characteristic (ROC) curve analysis was also performed. Postoperative outcomes, including acute kidney injury (AKI), hospitalization duration, and intensive care unit (ICU) admission, were also evaluated.

Results Among 1302 patients, 158 patients (12.1\%) received an intraoperative RBC transfusion. Multivariate logistic regression analysis demonstrated that the risk factors for RBC transfusion were the LM ratio, hemoglobin, 6\% hydroxyethyl starch amount, and positive surgical margin. The area under the ROC curve of $\mathrm{LM}$ ratio was 0.706 (cut-off $=4.3$ ). The $\mathrm{LM}$ ratio at $\leq 4.3$ was significantly related to transfusion in multivariate-adjusted analysis (odds ratio $=4.598, P<0.001$ ). AKI and ICU admission were significantly higher, and the hospitalization duration was significantly longer in patients with RBC transfusion.

Conclusions The LM ratio was a risk factor for RBC transfusion in radical retropubic prostatectomy. The optimal cut-off value of the LM ratio to predict transfusion was 4.3. RBC transfusion was associated with poor postoperative outcomes. Therefore, our results suggest that the LM ratio provide useful information on RBC transfusion in radical retropubic prostatectomy.
\end{abstract}

Keywords Lymphocyte/monocyte ratio $\cdot$ Radical retropubic prostatectomy $\cdot$ Transfusion · Acute kidney injury $\cdot$ Intensive care unit admission $\cdot$ Hospitalization duration

Yongsoo Lee

thisisrio@naver.com

Young-Kug Kim

kyk@amc.seoul.kr

1 Department of Anesthesiology and Pain Medicine, Asan Medical Center, University of Ulsan College of Medicine, 88, Olympic-ro 43-gil, Songpa-gu, Seoul 05505, Republic of Korea

2 Department of Urology, Asan Medical Center, University of Ulsan College of Medicine, Seoul 05505, Republic of Korea

3 Department of Anesthesiology and Pain Medicine, Uijeongbu Eulji Medical Center, Eulji University School of Medicine, 712, Dongil-ro, Uijeongbu-si, Gyeonggi-do 11759, Republic of Korea

\section{Introduction}

Radical prostatectomy is a mainstay of treatment in patients with prostate cancer [1]. Even if robotic or laparoscopic approaches for radical prostatectomy have become increasingly popular, radical retropubic prostatectomy is still widely performed, especially in prostate cancer patients with optic neuropathy, increased intracranial pressure, or severe obstructive lung disease [2]. However, radical retropubic prostatectomy has the risk of significant blood loss because of rich venous supply of the prostate [3]. The mean estimated blood loss ranged from 450 to $740 \mathrm{~mL}$ and the red blood cell (RBC) transfusion rate was between 3.4 and $3.8 \%$ in patients who underwent radical retropubic prostatectomy [4, 5]. Although advances in the surgical and anesthetic strategies for radical retropubic prostatectomy have dramatically improved perioperative outcomes, blood loss 
during radical retropubic prostatectomy is still a major concern [3, 6]. Complications of intraoperative RBC transfusion include allergy, infection, hemolysis, and coagulopathy [7, 8]. Furthermore, RBC transfusion may be associated with acute kidney injury (AKI), cancer recurrence, and mortality $[9,10]$. Therefore, careful perioperative management, including risk factor evaluation, should be performed to reduce the chances of transfusion during radical retropubic prostatectomy.

The lymphocyte/monocyte (LM) ratio, an inflammationbased score, has been widely used to predict the prognosis of multiple malignant tumors because the host systemic inflammatory response has a significant effect on tumor proliferative activity and disease progression [11]. The LM ratio can predict the prognosis of patients with colorectal, ovarian, and esophageal cancers [11-13]. In addition, it may also be associated with infection in patients with liver cirrhosis, prediction of osteoporosis, and mortality of patients with coronavirus disease 2019 [14-17]. Furthermore, in patients with head and neck cancer, low lymphocyte count is related to increased tissue adhesion or tissue damage [18]. Monocytes are involved in tumorigenesis, angiogenesis, invasion, migration, and metastasis [19]. Consequently, LM ratio may be linked to tissue inflammation, tissue adhesion, tissue damage, bleeding, and subsequent blood transfusion. However, no studies to date have reported on the association of the LM ratio with blood transfusion during radical retropubic prostatectomy.

Therefore, we tried to identify the independent risk factors, including the LM ratio, associated with intraoperative $\mathrm{RBC}$ transfusion in patients with prostate cancer who underwent radical retropubic prostatectomy.

\section{Materials and methods}

\section{Patients}

This large, single-center, observational study retrospectively analyzed data from patients who underwent radical retropubic prostatectomy between March 2009 and December 2020. Patients with other malignancy, incomplete medical record, and other combined surgeries were excluded. This study was approved by the institutional review board of Asan Medical Center (approval No. 2020-0271). This manuscript adheres to the applicable STROBE guidelines.

\section{Anesthesia protocol}

All patients underwent routine hemodynamic monitoring, which comprised electrocardiography, pulse oximetry, noninvasive blood pressure monitoring, end-tidal carbon dioxide concentration measurement, and bispectral index measurement. All patients were induced with propofol or thiopental for anesthesia; after losing consciousness, patients were administered rocuronium for muscle relaxation. Anesthesia was maintained with sevoflurane or desflurane and remifentanil infusion, according to the anesthesiologist's preference. Sevoflurane and desflurane were adjusted to maintain a bispectral index of 40-60. Medical air containing $50 \%$ oxygen was supplied. The ventilation setting was a $6-8 \mathrm{~mL} / \mathrm{kg}$ tidal volume of ideal body weight and an inspiratory to an expiratory ratio of $1: 2$. The respiratory rate was adjusted to maintain an end-tidal carbon dioxide concentration of $30-35 \mathrm{cmH}_{2} \mathrm{O}$. Arterial blood pressure was continuously monitored by radial arterial catheterization. If the systolic arterial blood pressure fell below $80 \mathrm{mmHg}$ or heart rate fell below 60 beats/minute, fluids and/or drugs such as ephedrine or phenylephrine were administered. Crystalloid fluids such as plasma solution A or Ringer's lactate solution were administered at a rate of $4-6 \mathrm{~mL} / \mathrm{kg} / \mathrm{hr}$. A $6 \%$ hydroxyethyl starch solution was administered according to our institutional protocol based on the patients' arterial blood pressure, heart rate, and blood loss. RBCs were transfused into patients who had hemoglobin concentrations $<8 \mathrm{~g} / \mathrm{dL}$ during surgery. After the procedure, the neuromuscular blockade was reversed by neostigmine-glycopyrrolate mixture or sugammadex, according to the anesthesiologist's preference.

\section{Surgical protocol}

The patient was placed in a supine position and was slightly hyperextended at approximately 20 degrees to elevate the pelvis and to facilitate surgical exposure. Vertical midline and extraperitoneal incisions were made, extending from just above the pubic symphysis to almost below the umbilicus. Fatty tissue covering the prostate and lateral pelvic side walls was carefully dissected to expose the space of Retzius. The endopelvic fascia was opened near the pelvic sidewall on both sides of the prostate. The puboprostatic ligaments were incised to expose the apex of the prostate. The dorsal venous complex was ligated to reduce bleeding. Pelvic lymph node dissection was proceeded based on clinical risk factors [20]. The anterior urethra was cut sharply to ensure the length of the striated urethral sphincter remained as long as possible. While pulling the foley catheter toward the bladder, the posterior aspect of the prostate and both pedicles were carefully dissected along with the neurovascular bundles. After prostate dissection, the vasa deferentia were cut and the seminal vesicles were dissected directly between the remaining bladder neck and prostate. After bladder neck reconstruction, vesicourethral anastomosis was performed. 


\section{Data collection}

The medical records of all patients were reviewed. The preoperative variables that were collected for each patient included age, body mass index, American Society of Anesthesiologist (ASA) physical status, history of abdominal surgery, comorbidities (hypertension/diabetes mellitus/ coronary artery disease/heart failure/cerebrovascular accident), medications (beta blocker/alpha blocker/angiotensin-converting enzyme inhibitor [ACEi] or angiotensin II receptor blocker $[\mathrm{ARB}] /$ calcium channel blocker), tumor stage, Gleason score on biopsy, neoadjuvant chemotherapy, neoadjuvant androgen deprivation therapy, and preoperative laboratory values (prostate-specific antigen, hemoglobin, red cell distribution width [RDW], platelets, white blood cells, lymphocytes, neutrophils, monocytes, neutrophil/lymphocyte [NL] ratio, platelet/lymphocyte [PL] ratio, LM ratio, glomerular filtration rate [GFR], uric acid, albumin, prothrombin time, and activated partial thromboplastin time [aPTT]). Heart failure was defined as an ejection fraction of $<40 \%$. The GFR was calculated using the Chronic Kidney Disease Epidemiology Collaboration equation [21, 22].

Collected intraoperative variables included operation duration, crystalloid amount, $6 \%$ hydroxyethyl starch amount, and Gleason score of specimen. The number of patients with extracapsular extension, positive surgical margin, seminal vesical invasion, and pelvic lymph node dissection was also recorded. Extracapsular extension was defined as tumor extension into the periprostatic soft tissue [23]. Positive surgical margin was defined as the presence of cancer cells at the inked margins[24]. Seminal vesical invasion was defined as penetration of the muscular coat of the seminal vesicles by the prostate tumor [25].

Postoperative outcomes including AKI, hospitalization duration, intensive care unit (ICU) admission, and 30 day mortality were assessed. Postoperative AKI was defined using the Kidney Disease: Improving Global Outcomes criteria as an increase in the serum creatinine concentration from the baseline by $0.3 \mathrm{mg} / \mathrm{dL}$ up to 2 postoperative days or by $50 \%$ up to 7 postoperative days [26-29]. Because urine output monitoring was not accurate in the general ward, the criterion for urine output was not analyzed in this study.

\section{Definition of the NL ratio, PL ratio, LM ratio, and RDW}

The NL ratio was defined as the absolute neutrophil count divided by the absolute lymphocyte count [30]. The PL ratio was defined as the absolute platelet count divided by the absolute lymphocyte count [31]. The LM ratio was defined as the absolute lymphocyte count divided by the absolute monocyte count [32]. The RDW was calculated as: (standard deviation of red cell volume/mean cell volume) $\times 100 \%$.
A range between 11.5 and $14.5 \%$ constituted normal RDW values [33]. The NL ratio, PL ratio, LM ratio, and RDW were measured on peripheral blood samples obtained within 5 days before surgery.

\section{Statistical analysis}

Categorical variables are expressed as the number (\%), and continuous variables are expressed as the mean \pm standard deviation. Categorical variables were compared using the chi-square test or Fisher's exact test, and continuous variables were compared using the Student's $t$ test between the non-transfusion and transfusion groups. Univariate and multivariate logistic regression analyses were performed to identify independent risk factors for RBC transfusion during radical retropubic prostatectomy. The most relevant factors associated with RBC transfusion, based on statistical considerations, biological plausibility, and clinical importance, were included in a univariate logistic regression analysis. Multivariate logistic regression analysis using the enter method included all covariates with $P<0.05$ from the univariate logistic regression analysis.

The ability of the preoperative LM ratio for predicting $\mathrm{RBC}$ transfusion during radical retropubic prostatectomy was determined by calculating the area under the receiver operating characteristic (ROC) curve using the trapezoid rule. The optimal cut-off value was determined by the maximum value of sensitivity and specificity. un adjusted and multivariate adjusted odds ratios (ORs) were used to assess predictive value of intraoperative RBC transfusion after dichotomizing according to the optimal cut-off value of the LM ratio.

We evaluated the variance inflation factor to assess multicollinearity. We also evaluated logistic regression model performance using the Hosmer-Lemeshow goodness-of-fit statistic (measuring model calibration) and the C-statistic (measuring model discrimination). All statistical analyses were conducted using SPSS Statistics for Windows, version 21.0 (IBM Corp., Armonk, NY, USA), and Stata, version 13.1 (Stata Corp., College Station, TX, USA). P values $<0.05$ were considered statistically significant.

\section{Results}

A review of the medical records identified 1501 patients who underwent radical retropubic prostatectomy between March 2009 and December 2020. Of these patients, 199 patients were excluded because of other malignancy $(n=109)$, incomplete medical record $(n=88)$, and other combined surgeries $(n=2)$. Therefore, the study cohort comprised 1302 patients (Fig. 1). Of these patients, 158 patients $(12.1 \%)$ received an intraoperative RBC 


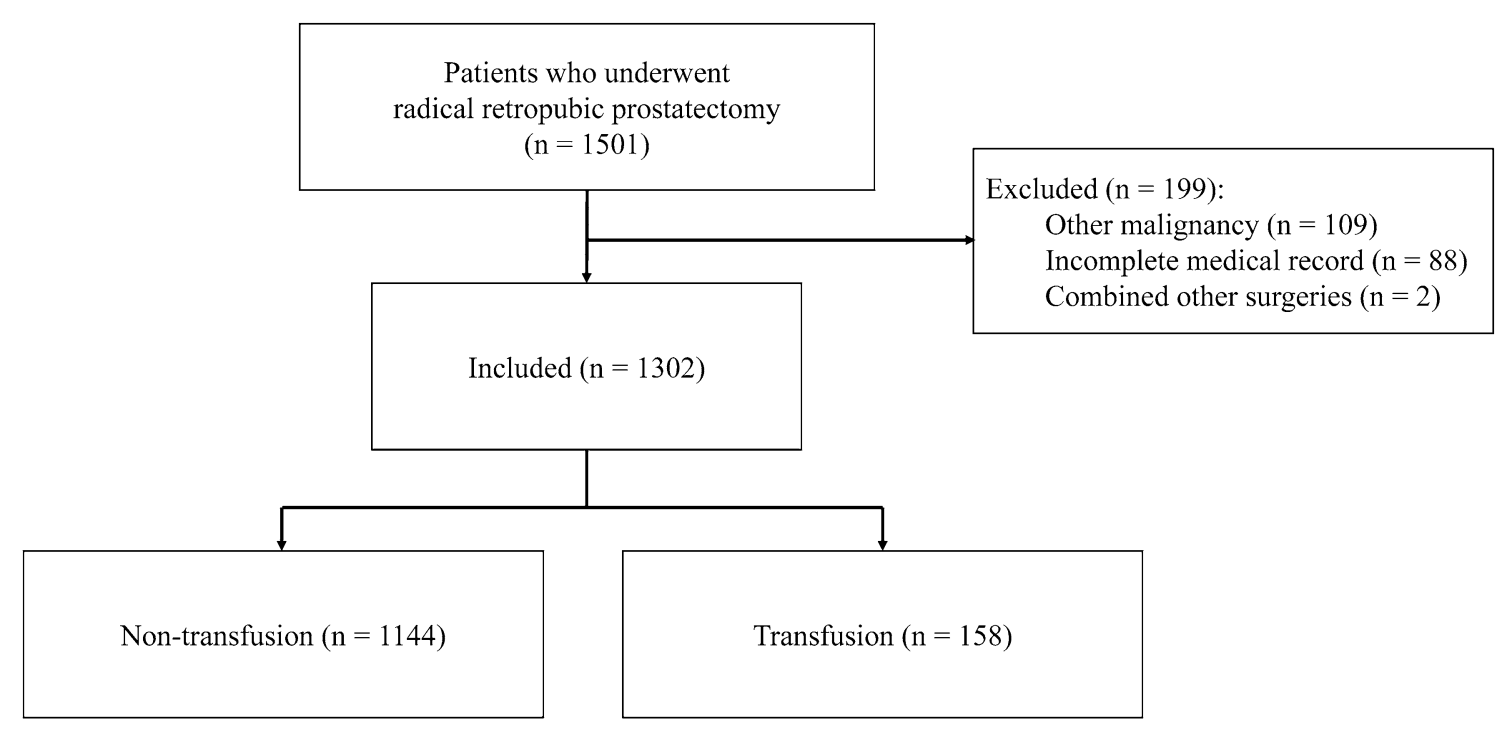

Fig. 1 Flowchart of the study protocol

transfusion during radical retropubic prostatectomy. In the transfusion group, the maximal amount of RBC transfusion was 8 units, and the mean amount of RBC transfusion was $1.7 \pm 0.9$ units during surgery.

The demographic and preoperative laboratory data of the 1302 patients are summarized in Table 1. Age, history of abdominal surgery, ACEi or ARB, prostate-specific antigen, RDW, neutrophils, monocytes, NL ratio, PL ratio, prothrombin time, and aPTT were significantly higher in the transfusion group than in the non-transfusion group. Hemoglobin, lymphocytes, and the LM ratio were significantly lower in the transfusion group.

Intraoperative variables are shown in Table 2. Operation duration, crystalloid amount, $6 \%$ hydroxyethyl starch amount, Gleason score of specimen, positive surgical margin, and seminal vesical invasion were significantly higher in the transfusion group.

Univariate logistic regression analysis showed that age, history of abdominal surgery, ACEi or ARB, Gleason score on biopsy, hemoglobin, RDW, NL ratio, PL ratio, LM ratio, GFR, serum albumin level, aPTT, $6 \%$ hydroxyethyl starch amount, positive surgical margin, and seminal vesical invasion were significantly associated with RBC transfusion during radical retropubic prostatectomy (Table 3). Multivariate logistic regression analysis demonstrated that the independent risk factors for intraoperative $\mathrm{RBC}$ transfusion were $\mathrm{LM}$ ratio $(\mathrm{OR}=0.656,95 \%$ confidence interval $[\mathrm{CI}]=0.553-0.777, P<0.001)$, hemoglobin $(\mathrm{OR}=0.619,95 \% \mathrm{CI}=0.521-0.735, P<0.001)$, $6 \%$ hydroxyethyl starch amount $(\mathrm{OR}=1.003,95 \%$ $\mathrm{CI}=1.002-1.004, P<0.001)$, and positive surgical margin $(\mathrm{OR}=1.616,95 \% \mathrm{CI}=1.066-2.451, P=0.024)$, and (Fig. 2). The highest variance inflation factor was 1.732 .
The Hosmer-Lemeshow goodness-of-fit statistic for the model was 0.222 , and the $\mathrm{C}$-statistic was 0.858 .

The optimal cut-off value of the LM ratio was 4.3 , with a sensitivity of $72.8 \%$ and specificity of $65.7 \%$. Of the cohort study, 507 (38.9\%) patients had LM ratio $\leq 4.3$ and 794 $(61.0 \%)$ patients had LM ratio $>4.3$. Compared with the patients with $\mathrm{LM}$ ratio $>4.3$, the patients with $\mathrm{LM}$ ratio $\leq 4.3$ had received more $\mathrm{RBC}$ transfusions in the unadjusted $(\mathrm{OR}=5.124,95 \% \mathrm{CI} 3.536-7.425, P<0.001)$ and multivariate-adjusted analyses $(\mathrm{OR}=4.598,95 \% \mathrm{CI}=2.841-7.443$, $P<0.001)$ (Fig. 3).

The postoperative outcomes of patients were shown in Table 4. AKI was significantly higher in the transfusion group than in the non-transfusion group (18 [11.4\%] vs. 67 [5.9\%], $P=0.008$ ). The hospitalization duration was significantly longer in the transfusion group than in the nontransfusion group $(12 \pm 6$ days vs. $10 \pm 4$ days, $P<0.001)$. Further, ICU admission was significantly higher in the transfusion group than in the non-transfusion group (5 [3.2\%] vs. 12 [1.5\%], $P=0.045)$. However, there was no significant difference 30 day mortality after surgery between both groups.

\section{Discussion}

In this study, the LM ratio, hemoglobin, $6 \%$ hydroxyethyl starch amount, and positive surgical margin were independent risk factors for intraoperative RBC transfusion in patients who underwent radical retropubic prostatectomy. The optimal cut-off value of the LM ratio to predict intraoperative $\mathrm{RBC}$ transfusion was 4.3. The patients with $\mathrm{LM}$ ratio $\leq 4.3$ had received more RBC transfusions in radical retropubic prostatectomy. Moreover, AKI and ICU admission were 
Table 1 Demographic and preoperative laboratory data

\begin{tabular}{|c|c|c|c|c|}
\hline Variables & $\begin{array}{l}\text { All patients } \\
(n=1302)\end{array}$ & $\begin{array}{l}\text { Non-transfusion } \\
(n=1144)\end{array}$ & $\begin{array}{l}\text { Transfusion } \\
(n=158)\end{array}$ & $P$ value \\
\hline Age, years & $67 \pm 6$ & $67 \pm 6$ & $68 \pm 6$ & 0.034 \\
\hline Body mass index, $\mathrm{kg} / \mathrm{m}^{2}$ & $24.7 \pm 2.7$ & $24.7 \pm 2.7$ & $24.4 \pm 2.8$ & 0.144 \\
\hline ASA physical status & & & & 0.320 \\
\hline$\leq 2$ & $1262(96.9)$ & $1111(97.1)$ & $151(95.6)$ & \\
\hline 3 & $40(3.1)$ & $33(2.9)$ & $7(4.4)$ & \\
\hline History of abdominal surgery & $248(19.0)$ & $208(18.2)$ & $40(25.3)$ & 0.032 \\
\hline \multicolumn{5}{|l|}{ Comorbidities } \\
\hline Hypertension & $406(46.4)$ & $524(45.8)$ & $80(50.6)$ & 0.254 \\
\hline Diabetes mellitus & $229(17.6)$ & $196(17.1)$ & $33(20.9)$ & 0.245 \\
\hline Coronary artery disease & $56(4.3)$ & $46(4.0)$ & $10(6.3)$ & 0.180 \\
\hline Heart failure & $3(0.2)$ & $3(0.3)$ & $0(0.0)$ & $>0.999$ \\
\hline Cerebrovascular accident & $37(2.8)$ & $31(2.7)$ & $6(3.8)$ & 0.441 \\
\hline \multicolumn{5}{|l|}{ Medications } \\
\hline Beta blocker & $57(5.4)$ & $57(5.2)$ & $10(6.7)$ & 0.464 \\
\hline Alpha blocker & $49(4.0)$ & $46(4.3)$ & $3(2.0)$ & 0.179 \\
\hline ACEi or ARB & $295(22.7)$ & $246(21.5)$ & $49(31.0)$ & 0.007 \\
\hline Calcium channel blocker & $265(21.5)$ & $224(20.7)$ & $41(27.2)$ & 0.071 \\
\hline Tumor stage & & & & 0.735 \\
\hline 1 & $794(61.0)$ & $700(61.2)$ & $94(59.5)$ & \\
\hline 2 & $31(2.4)$ & $27(2.4)$ & $4(2.5)$ & \\
\hline 3 & $431(33.1)$ & $379(33.1)$ & $52(32.9)$ & \\
\hline 4 & $46(3.5)$ & $38(3.3)$ & $8(5.1)$ & \\
\hline Gleason score on biopsy, points & $6.9 \pm 1.0$ & $6.9 \pm 1.0$ & $7.1 \pm 1.2$ & 0.069 \\
\hline Neoadjuvant chemotherapy & $7(0.5)$ & $5(0.4)$ & $2(1.3)$ & 0.205 \\
\hline Neoadjuvant androgen deprivation therapy & $155(11.9)$ & $131(11.5)$ & $24(15.2)$ & 0.174 \\
\hline \multicolumn{5}{|l|}{ Preoperative laboratory values } \\
\hline Prostate specific antigen, $\mathrm{ng} / \mathrm{ml}$ & $14.1 \pm 28.4$ & $13.6 \pm 29.2$ & $17.8 \pm 22.0$ & 0.035 \\
\hline Hemoglobin, g/dL & $14.1 \pm 3.0$ & $14.1 \pm 1.3$ & $13.2 \pm 1.8$ & $<0.001$ \\
\hline RDW, \% & $12.9 \pm 1.0$ & $12.8 \pm 0.8$ & $13.2 \pm 1.8$ & 0.003 \\
\hline Platelets, $10^{3} / \mu \mathrm{L}$ & $222.1 \pm 54.2$ & $222.7 \pm 53.3$ & $218.4 \pm 56.0$ & 0.340 \\
\hline White blood cells, $10^{3} / \mu \mathrm{L}$ & $6.2 \pm 1.7$ & $6.2 \pm 1.7$ & $6.2 \pm 1.9$ & 0.998 \\
\hline Lymphocytes, $\%$ & $33.6 \pm 8.8$ & $34.0 \pm 8.6$ & $30.4 \pm 9.2$ & $<0.001$ \\
\hline Neutrophils, $\%$ & $55.8 \pm 9.5$ & $55.5 \pm 9.4$ & $58.2 \pm 10.1$ & 0.001 \\
\hline Monocytes, $\%$ & $7.2 \pm 2.2$ & $7.0 \pm 2.1$ & $8.3 \pm 2.4$ & $<0.001$ \\
\hline NL ratio & $1.9 \pm 1.2$ & $1.9 \pm 1.2$ & $2.3 \pm 1.5$ & 0.001 \\
\hline PL ratio & $120.3 \pm 61.7$ & $118.5 \pm 61.9$ & $133.3 \pm 58.5$ & 0.005 \\
\hline LM ratio & $5.1 \pm 2.8$ & $5.3 \pm 2.9$ & $3.9 \pm 1.6$ & $<0.001$ \\
\hline $\mathrm{GFR}, \mathrm{mL} / \mathrm{min} / 1.73 \mathrm{~m}^{2}$ & $80.1 \pm 12.7$ & $80.4 \pm 12.2$ & $77.9 \pm 15.8$ & 0.057 \\
\hline Uric acid, $\mathrm{mmol} / \mathrm{L}$ & $5.5 \pm 1.3$ & $5.5 \pm 1.3$ & $5.5 \pm 1.5$ & 0.882 \\
\hline Albumin, g/dL & $4.0 \pm 0.5$ & $4.0 \pm 0.5$ & $4.0 \pm 0.4$ & 0.090 \\
\hline Prothrombin time, INR & $0.98 \pm 0.06$ & $0.98 \pm 0.06$ & $0.99 \pm 0.06$ & 0.007 \\
\hline aPTT, sec & $27.5 \pm 2.5$ & $27.5 \pm 2.5$ & $27.9 \pm 2.4$ & 0.043 \\
\hline
\end{tabular}

Continuous variables are presented as mean \pm standard deviation, and categorical variables are presented as numbers $(\%)$

$A S A$ American Society of Anesthesiologists; $A C E i$ angiotensin converting enzyme inhibitor; $A R B$ angiotensin II receptor blocker; $R D W$ red cell distribution width; $N L$ neutrophil/lymphocyte; $P L$ platelet/lymphocyte; $L M$ lymphocyte/monocyte; GFR glomerular filtration rate; INR international normalized ratio, aPTT activated partial thromboplastin time 
Table 2 Intraoperative variables

\begin{tabular}{llllr}
\hline Variables & $\begin{array}{l}\text { All patients } \\
(n=1302)\end{array}$ & $\begin{array}{l}\text { Non-transfusion } \\
(n=1144)\end{array}$ & $\begin{array}{l}\text { Transfusion } \\
(n=158)\end{array}$ & $P$ value \\
\hline Operation duration, min & $160 \pm 39$ & $155 \pm 36$ & $189 \pm 45$ & $<0.001$ \\
Crystalloid amount, mL & $1667 \pm 711$ & $1575 \pm 629$ & $2326 \pm 903$ & $<0.001$ \\
6\% hydroxyethyl starch amount, $\mathrm{mL}$ & $260 \pm 334$ & $216 \pm 295$ & $577 \pm 421$ & $<0.001$ \\
Gleason score of specimen, points & $7.2 \pm 0.8$ & $7.2 \pm 0.8$ & $7.4 \pm 0.9$ & 0.011 \\
Extracapsular extension & $605(46.5)$ & $521(45.5)$ & $84(53.2)$ & 0.072 \\
Positive surgical margin & $497(38.2)$ & $421(36.8)$ & $76(48.1)$ & 0.006 \\
Seminal vesical invasion & $186(14.3)$ & $153(13.4)$ & $33(21.0)$ & 0.010 \\
Pelvic lymph node dissection & $1157(88.9)$ & $1019(89.1)$ & $138(87.3)$ & 0.517 \\
\hline
\end{tabular}

Continuous variables are presented as mean \pm standard deviation, and categorical variables are presented as numbers $(\%)$

significantly higher and the hospitalization duration was significantly longer in patients with RBC transfusion. To the best of our knowledge, this study is the first to evaluate the association between the LM ratio and RBC transfusion in radical retropubic prostatectomy.

In this study, the LM ratio was an independent risk factor for RBC transfusion in patients who underwent radical retropubic prostatectomy. Complete blood count, which is tested in routine clinical practice, is a cheap, easy to interpret, and readily available diagnostic laboratory test. It is widely used for the diagnosis and monitoring of several diseases apart from hematologic diseases [34]. Ongoing research suggests the utility of inflammatory biomarkers such as the LM ratio, NL ratio, and PL ratio, which are all based on the proportions of different types of white blood cells, in the prognosis of various diseases $[31,34]$. The LM ratio, which is the ratio of the absolute lymphocyte count to the absolute monocyte count, allows us to assess the systemic inflammation status with a routine blood test [35]. A lower LM ratio indicates lower lymphocyte levels or higher monocyte levels in the peripheral blood. Lymphocytes exhibit an antitumor effect by inducing a cytotoxic immune response [36]. Consequently, low lymphocyte counts are considered to indicate immunological incompetence for malignant diseases and are a prognostic marker for oncological outcomes [18]. Monocytes are involved in tumorigenesis, angiogenesis, invasion, migration, and metastasis and are involved suppression of the body's autoimmune response against tumor cells [19]. Therefore, the LM ratio is being studied as a potential prognosis predictor in cancer patients [11,37-39]. Besides being a novel marker of the baseline inflammatory response, the LM ratio decreases in several clinical conditions, including bacterial infections, osteoporosis, stroke, acute rheumatic fever, and coronary artery atherosclerosis [14, 16, 40-43]. Because an unexpected decrease in the LM ratio may be associated with poor outcomes in various clinical circumstances, its clinical application as a prognostic factor is being closely investigated.
Specifically, the underlying mechanisms of the association of low LM ratio and transfusion are not fully explained. The possible mechanisms are tissue inflammation, adhesion, and damage. Inflammation and cancer are closely related [44]. Chronic inflammation is associated with of the occurrence of several cancers $[45,46]$. In contrast, cancer can introduce and propagate local inflammation that causes tumor growth and invasion [44]. Systemic inflammation is a key aspect of the immune response caused tissue damage or infection and helps in the recruitment of circulating immune cells to the tissue $[44,47]$. Consequently, preoperative inflammation, represented by abnormal inflammatory biomarker such as the LM ratio, is likely to be associated with increased preoperative tissue adhesion or intraoperative tissue damage compared with normal inflammatory biomarkers. For these reasons, a decreased LM ratio may predict $\mathrm{RBC}$ transfusion during radical retropubic prostatectomy.

In this study, the LM ratio $\leq 4.3$ predicted $\mathrm{RBC}$ transfusion during radical retropubic prostatectomy. The patients with $\mathrm{LM}$ ratio $\leq 4.3$ received more $\mathrm{RBC}$ transfusions than those with $\mathrm{LM}$ ratio $>4.3$. The cut-off values of the LM ratio varies, ranging from 1.5 to $5.3[11,14,37-40,43,48]$. The LM ratio $\leq 1.53$ was significantly associated with a severe Klebsiella pneumonia infection [48]. In patients with liver cirrhosis, the LM ratio $\leq 2.06$ was an independent prognostic factor for bacterial infection among other inflammatorybased biomarkers such as the NL ratio, monocytes, and C-reactive protein [14]. The cut-off value of the LM ratio to predict severe coronary artery atherosclerosis was 5.06 [43]. In patients with acute ischemic stroke, the LM ratio $\leq 2.99$ was an independent prognostic factor for stroke severity and prognosis [40]. Therefore, the patients with decreased LM ratio should be carefully managed to reduce intraoperative transfusion in radical retropubic prostatectomy.

The present study also revealed that hemoglobin, $6 \%$ hydroxyethyl starch amount, and positive surgical margin were significantly associated with RBC transfusion in patients underwent radical retropubic prostatectomy. 
Table 3 Univariate logistic regression analyses of factors associated with red blood cell blood transfusion

\begin{tabular}{|c|c|c|}
\hline \multirow[t]{2}{*}{ Variables } & \multicolumn{2}{|l|}{ Univariate } \\
\hline & OR $(95 \% \mathrm{CI})$ & $P$ value \\
\hline Age & $1.032(1002-1.063)$ & 0.035 \\
\hline Body mass index & $0.955(0.899-1.016)$ & 0.144 \\
\hline \multicolumn{3}{|l|}{ ASA physical status } \\
\hline$\leq 2$ & 1 & \\
\hline 3 & $1.561(0.678-3.590)$ & 0.295 \\
\hline History of abdominal surgery & $1.525(1.034-2.250)$ & 0.033 \\
\hline Hypertension & $1.214(0.870-1.693)$ & 0.254 \\
\hline Diabetes mellitus & $1.277(0.845-1.930)$ & 0.246 \\
\hline Coronary artery disease & $1.613(0.797-3.264)$ & 0.184 \\
\hline Beta blocker & $1.296(0.647-2.596)$ & 0.465 \\
\hline Alpha blocker & $0.454(0.140-1.479)$ & 0.190 \\
\hline ACEi or ARB & $1.641(1.139-2.365)$ & 0.008 \\
\hline Calcium channel blocker & $1.428(0.969-2.104)$ & 0.072 \\
\hline \multicolumn{3}{|l|}{ Tumor stage } \\
\hline 1 & 1 & \\
\hline 2 & $1.103(0.378-3.222)$ & 0.857 \\
\hline 3 & $1.022(0.712-1.466)$ & 0.907 \\
\hline 4 & $1.568(0.710-3.462)$ & 0.266 \\
\hline Gleason score on biopsy & $1.181(1.010-1.382)$ & 0.037 \\
\hline Neoadjuvant chemotherapy & $2.921(0.562-15.182)$ & 0.203 \\
\hline Neoadjuvant androgen deprivation therapy & $1.385(0.865-2.218)$ & 0.175 \\
\hline \multicolumn{3}{|l|}{ Preoperative laboratory test } \\
\hline Prostate specific antigen & $1.003(0.999-1.008)$ & 0.120 \\
\hline Hemoglobin & $0.630(0.560-0.708)$ & $<0.001$ \\
\hline Platelet & $0.998(0.995-1.002)$ & 0.340 \\
\hline RDW & $1.449(1.244-1.689)$ & $<0.001$ \\
\hline NL ratio & $1.206(1.067-1.364)$ & 0.003 \\
\hline PL ratio & $1.003(1.001-1.005)$ & 0.030 \\
\hline LM ratio & $0.642(0.572-0.719)$ & $<0.001$ \\
\hline GFR & $0.986(0.974-0.998)$ & 0.021 \\
\hline Uric acid & $1.010(0.889-1.147)$ & 0.882 \\
\hline Albumin & $0.572(0.342-0.958)$ & 0.034 \\
\hline aPTT & $1.062(1.001-1.126)$ & 0.046 \\
\hline $6 \%$ hydroxyethyl starch amount & $1.003(1.002-1.003)$ & $<0.001$ \\
\hline Gleason score of specimens & $0.992(0.692-1.421)$ & 0.964 \\
\hline Extracapsular extension & $1.357(0.972-1.895)$ & 0.072 \\
\hline Positive surgical margin & $1.592(1.139-2.224)$ & 0.006 \\
\hline Seminal vesical invasion & $1.724(1.133-2.623)$ & 0.011 \\
\hline Pelvic lymph node dissection & $0.846(0.511-1.402)$ & 0.517 \\
\hline
\end{tabular}

OR odds ratio; $C I$ confidence interval; ASA American Society of Anesthesiologists; ACEi Angiotensin converting enzyme inhibitor; $A R B$ angiotensin II receptor blocker; $R D W$ red cell distribution width; $N L$ neutrophil/lymphocyte; $P L$ platelet/lymphocyte; $L M$ lymphocyte/monocyte; GFR glomerular filtration rate; $a P T T$ activated partial thromboplastin time
Preoperative anemia is well-known risk factor of RBC transfusion $[49,50]$. In our results, preoperative hemoglobin level was significantly lower in transfusion group than in nontransfusion group. Therefore, preoperative hemoglobin may affect intraoperative RBC transfusion in radical retropubic prostatectomy. In addition, $6 \%$ hydroxyethyl starch also can be a risk factor of $\mathrm{RBC}$ transfusion [51]. In meta-analysis of colloid and crystalloid administrations in critical ill patients, starches probably slightly increase the need for blood transfusion [51]. Furthermore, microscopically positive resection 


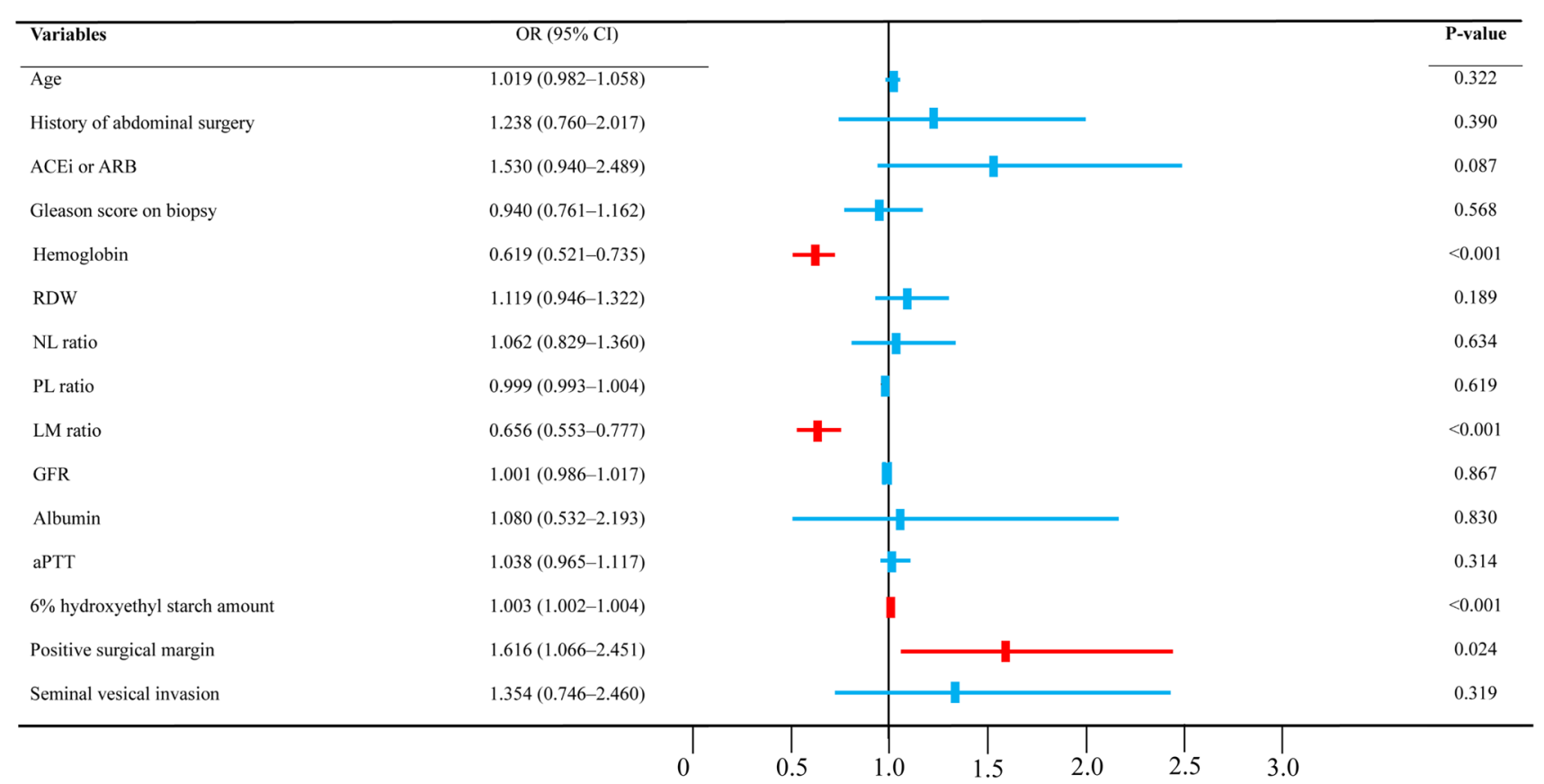

Fig. 2 Multivariate logistic regression analysis of factors associated with red blood cell transfusion during radical retropubic prostatectomy. OR, odds ratio; CI, confidence interval. ACEi, angiotensin converting enzyme inhibitor; $\mathrm{ARB}$, angiotensin II receptor blocker;
RDW, red cell distribution width; NL, neutrophil/lymphocyte; PL, platelet/lymphocyte; LM, lymphocyte/monocyte; GFR, glomerular filtration rate; aPTT, activated partial thromboplastin time

margin represents a biologically more aggressive tumor, and is accompanied by more microvascular invasions and positive lymph nodes in patients with pancreatic cancer [52]. Therefore, clinicians should be cautious to avoid RBC transfusion in patients with low preoperative hemoglobin, administration of $6 \%$ hydroxyethyl starch, or positive surgical margin during radical retropubic prostatectomy.

Patients who had been treated with ACEi or ARB were received more $\mathrm{RBC}$ transfusion than those who had not been treated with these drugs. ACEi and ARB are widely administered to control hypertension. They are also indicated for the treatment of patients at a high risk for coronary artery disease, after myocardial infarction, with dilated cardiomyopathy, or with chronic kidney disease [53]. The association between ACEi and ARB and blood

Fig. 3 Predictive value of the LM ratio $\leq 4.3$ for red blood cell transfusion during radical retropubic prostatectomy compared with the LM ratio $>4.3$. The multivariate-adjusted odds ratio was determined using the variables shown in Table 3. LM, lymphocyte/monocyte; OR, odds ratio; $\mathrm{CI}$, confidence interval

Table 4 Postoperative outcomes

\begin{tabular}{llllr}
\hline Outcomes & $\begin{array}{l}\text { All patients } \\
(n=1302)\end{array}$ & $\begin{array}{l}\text { Non-transfusion } \\
(n=1144)\end{array}$ & $\begin{array}{l}\text { Transfusion } \\
(n=158)\end{array}$ & $P$ value \\
\hline Acute kidney injury & $85(6.5)$ & $67(5.9)$ & $18(11.4)$ & 0.008 \\
Hospitalization duration, days & $10 \pm 4$ & $10 \pm 4$ & $12 \pm 6$ & $<0.001$ \\
Intensive care unit admission & $17(1.3)$ & $12(1.0)$ & $5(3.2)$ & 0.045 \\
30-days mortality & $1(0.1)$ & $0(0.0)$ & $1(0.6)$ & 0.121 \\
\hline
\end{tabular}

Continuous variables are presented as mean \pm standard deviation, and categorical variables are presented as numbers $(\%)$ 
transfusion is not adequately reported in the literature. In older patients taking anticoagulants, the use of ACEi increases the risk of bleeding in a dose-dependent manner [54]. In that study, the attributable risk of bleeding associated with ACEi treatment was $21 \%$. In patients with myocardial infarction, clinically significant bleeding was more frequent in patients treated with clopidogrel and ACEi than in patients treated with clopidogrel only because both clopidogrel and ACEi are metabolized by the same hepatic carboxylesterase 1 [55]. Although ACEi or ARB use was not independently associated with RBC transfusion in this study, the association needs to be interpreted cautiously and needs further study.

In this study, AKI and ICU admission were higher and the hospitalization duration was longer in patients with RBC transfusion in radical retropubic prostatectomy. Transfusion and AKI are independently associated with each other [9]. Blood storage-related biochemical and morphological changes lead to hemolysis and pro-inflammatory molecule accumulation and may affect postoperative AKI [9]. Furthermore, transfusion also can be associated with poor outcomes. Transfusion increased the hospitalization duration and ICU admission [56, 57]. The patients who received RBC transfusion are more likely to develop poor postoperative outcomes. Therefore, these patients should be carefully managed to improve postoperative outcomes in radical retropubic prostatectomy.

This study had some limitations. First, because this study had a retrospective design, we could not evaluate all covariates that may have affected the analysis. Therefore, our study may be, at least in part, influenced by selection bias. However, we included almost all covariate factors related to transfusion in patients who underwent radical retropubic prostatectomy. Second, this study was performed at a single, highly experienced institution. Therefore, our finding should be interpreted cautiously.

\section{Conclusions}

The LM ratio was an independent risk factor for RBC transfusion in patients who underwent radical retropubic prostatectomy. The optimal cut-off value of the LM ratio to predict intraoperative RBC transfusion was 4.3. Compared with the patients with $\mathrm{LM}$ ratio $>4.3$, the patients with $\mathrm{LM}$ ratio $\leq 4.3$ had received more $\mathrm{RBC}$ transfusions. Moreover, $\mathrm{AKI}$ and ICU admission were higher and the hospitalization duration was longer in patients with RBC transfusion. Our results suggest that the LM ratio provides useful information on intraoperative RBC transfusion in radical retropubic prostatectomy.

\section{Declarations}

Conflict of interest The authors have no conflicts of interest.

\section{References}

1. Mottet N, Bellmunt J, Bolla M, Briers E, Cumberbatch MG, De Santis M, Fossati N, Gross T, Henry AM, Joniau S, Lam TB, Mason MD, Matveev VB, Moldovan PC, van den Bergh RCN, Van den Broeck T, van der Poel HG, van der Kwast TH, Rouvière $\mathrm{O}$, Schoots IG, Wiegel T, Cornford P. EAU-ESTRO-SIOG guidelines on prostate cancer. Part 1: screening, diagnosis, and local treatment with curative intent. Eur Urol. 2017;71(4):618-29. https://doi.org/10.1016/j.eururo.2016.08.003.

2. Gainsburg DM. Anesthetic concerns for robotic-assisted laparoscopic radical prostatectomy. Minerva Anestesiol. 2012;78(5):596-604.

3. Nuttall GA, Cragun MD, Hill DL, Morris TJ, Decker PA, Blute ML, Patterson DE, Warner DO. Radical retropubic prostatectomy and blood transfusion. Mayo Clin Proc. 2002;77(12):1301-5. https://doi.org/10.4065/77.12.1301.

4. Djavan B, Agalliu I, Laze J, Sadri H, Kazzazi A, Lepor H. Blood loss during radical prostatectomy: impact on clinical, oncological and functional outcomes and complication rates. BJU Int. 2012;110(1):69-75. https://doi.org/10.1111/j.1464-410X.2011. 10812.x.

5. Kordan Y, Barocas DA, Altamar HO, Clark PE, Chang SS, Davis R, Herrell SD, Baumgartner R, Mishra V, Chan RC, Smith JA Jr, Cookson MS. Comparison of transfusion requirements between open and robotic-assisted laparoscopic radical prostatectomy. BJU Int. 2010;106(7):1036-40. https://doi.org/10.1111/j.1464-410X. 2010.09233.x.

6. Kirollos MM. Bleeding following retropubic prostatectomy: simple digital rectal pressure could be lifesaving. J Urol. 1998;160(2):477-8. https://doi.org/10.1016/s0022-5347(01) 62928-8

7. Sharma S, Sharma P, Tyler LN. Transfusion of blood and blood products: indications and complications. Am Fam Physician. 2011;83(6):719-24.

8. Cirasino L, Barosi G, Torre M, Crespi S, Colombo P, Belloni PA. Preoperative predictors of the need for allogeneic blood transfusion in lung cancer surgery. Transfusion. 2000;40(10):1228-34. https://doi.org/10.1046/j.1537-2995.2000.40101228.x.

9. Karkouti K. Transfusion and risk of acute kidney injury in cardiac surgery. Br J Anaesth. 2012;109(Suppl 1):i29-38. https://doi.org/ $10.1093 / \mathrm{bja} / \mathrm{aes} 422$.

10. Tai YH, Wu HL, Mandell MS, Tsou MY, Chang KY. The association of allogeneic blood transfusion and the recurrence of hepatic cancer after surgical resection. Anaesthesia. 2020;75(4):464-71. https://doi.org/10.1111/anae.14862.

11. Tan D, Fu Y, Tong W, Li F. Prognostic significance of lymphocyte to monocyte ratio in colorectal cancer: a meta-analysis. Int J Surg (London, England). 2018;55:128-38. https://doi.org/10.1016/j. ijsu.2018.05.030.

12. Gong J, Jiang H, Shu C, Hu MQ, Huang Y, Liu Q, Li RF. Prognostic value of lymphocyte-to-monocyte ratio in ovarian cancer: a meta-analysis. J Ovarian Res. 2019;12(1):51. https://doi.org/10. 1186/s13048-019-0527-z.

13. Hu G, Liu G, Ma JY, Hu RJ. Lymphocyte-to-monocyte ratio in esophageal squamous cell carcinoma prognosis. Clin Chim Acta. 2018;486:44-8. https://doi.org/10.1016/j.cca.2018.07.029.

14. Piotrowski D, Sączewska-Piotrowska A, Jaroszewicz J, BorońKaczmarska A. Lymphocyte-to-monocyte ratio as the best simple 
predictor of bacterial infection in patients with liver cirrhosis. Int J Environ Res Public Health. 2020. https://doi.org/10.3390/ijerp h17051727.

15. Kamonvarapitak T, Matsuda A, Matsumoto S, Jamjittrong S, Sakurazawa N, Kawano Y, Yamada T, Suzuki H, Miyashita M, Yoshida H. Preoperative lymphocyte-to-monocyte ratio predicts postoperative infectious complications after laparoscopic colorectal cancer surgery. Int J Clin Oncol. 2020;25(4):633-40. https:// doi.org/10.1007/s10147-019-01583-y.

16. Gao K, Zhu W, Liu W, Ma D, Li H, Yu W, Li Q, Cao Y. The predictive role of monocyte-to-lymphocyte ratio in osteoporosis patient. Medicine (Baltimore). 2019;98(34): e16793. https://doi. org/10.1097/md.0000000000016793.

17. Ramos-Peñafiel CO, Santos-González B, Flores-López EN, Galván-Flores F, Hernández-Vázquez L, Santoyo-Sánchez A, OcaYemha RM, Bejarano-Rosales M, Rosas-González É, Olarte-Carrillo I, Martínez-Murillo C, Martínez-Tovar A. Usefulness of the neutrophil-to-lymphocyte, monocyte-to-lymphocyte and lymphocyte-to-platelet ratios for the prognosis of COVID-19-associated complications. Gac Med Mex. 2020;156(5):405-11. https://doi. org/10.24875/gmm.M20000428.

18. Hoffmann TK, Dworacki G, Tsukihiro T, Meidenbauer N, Gooding W, Johnson JT, Whiteside TL. Spontaneous apoptosis of circulating T lymphocytes in patients with head and neck cancer and its clinical importance. Clin Cancer Res. 2002;8(8):2553-62.

19. Coussens LM, Werb Z. Inflammation and cancer. Nature. 2002;420(6917):860-7. https://doi.org/10.1038/nature01322.

20. Djavan B, Kazzazi A, Dulabon L, Momtahen S, Dianat SS, Sand M, Cheetham P, Janetschek G, Lepor H, Graefen M. Indications and trends in pelvic lymph node dissection for prostate cancer. Eur Urol Suppl. 2011;10(3):e38-43.

21. Yu J, Hong B, Park JY, Lee Y, Hwang JH, Kong YG, Kim YK. Comparison of a significant decline in the glomerular filtration rate between ileal conduit and ileal neobladder urinary diversions after radical cystectomy: a propensity score-matched analysis. J Clin Med. 2020. https://doi.org/10.3390/jcm9072236.

22. Lim J, Kong YG, Kim YK, Hong B. Risk factors associated with decreased renal function after hand-assisted laparoscopic donor nephrectomy: a multivariate analysis of a single surgeon experience. Int J Med Sci. 2017;14(2):159-66. https://doi.org/10.7150/ ijms. 17585 .

23. McNeal JE, Villers AA, Redwine EA, Freiha FS, Stamey TA. Capsular penetration in prostate cancer. Significance for natural history and treatment. Am J Surg Pathol. 1990;14(3):240-7. https://doi.org/10.1097/00000478-199003000-00005.

24. Cheng L, Slezak J, Bergstralh EJ, Myers RP, Zincke H, Bostwick DG. Preoperative prediction of surgical margin status in patients with prostate cancer treated by radical prostatectomy. J Clin Oncol. 2000;18(15):2862-8. https://doi.org/10.1200/jco.2000. 18.15.2862.

25. Sofer M, Savoie M, Kim SS, Civantos F, Soloway MS. Biochemical and pathological predictors of the recurrence of prostatic adenocarcinoma with seminal vesicle invasion. J Urol. 2003;169(1):153-6. https://doi.org/10.1097/01.ju.0000042455. 02645.d0.

26. Kim HY, Kong YG, Park JH, Kim YK. Acute kidney injury after burn surgery: preoperative neutrophil/lymphocyte ratio as a predictive factor. Acta Anaesthesiol Scand. 2019;63(2):240-7. https://doi.org/10.1111/aas.13255.

27. Joung KW, Choi SS, Kong YG, Yu J, Lim J, Hwang JH, Kim YK. Incidence and risk factors of acute kidney injury after radical cystectomy: importance of preoperative serum uric acid level. Int J Med Sci. 2015;12(7):599-604. https://doi.org/10.7150/ijms. 12106.

28. Yu J, Park JY, Ha S, Hwang JH, Kim YK. C-reactive protein/ albumin ratio and acute kidney injury after radical cystectomy among elderly patients: a propensity score-matched analysis. Dis Markers. 2020;2020:8818445. https://doi.org/10.1155/2020/ 8818445.

29. Okusa MD, Davenport A. Reading between the (guide)lines-the KDIGO practice guideline on acute kidney injury in the individual patient. Kidney Int. 2014;85(1):39-48. https://doi.org/10.1038/ki. 2013.378.

30. Parlar H, Şaşkın H. Are pre and postoperative platelet to lymphocyte ratio and neutrophil to lymphocyte ratio associated with early postoperative AKI following CABG? Braz J Cardiovasc Surg. 2018;33(3):233-41. https://doi.org/10.21470/ 1678-9741-2017-0164.

31. Zhu S, Yang J, Cui X, Zhao Y, Tao Z, Xia F, Chen L, Huang J, Ma X. Preoperative platelet-to-lymphocyte ratio and neutrophilto-lymphocyte ratio as predictors of clinical outcome in patients with gallbladder cancer. Sci Rep. 2019;9(1):1823. https://doi.org/ 10.1038/s41598-018-38396-4.

32. Stotz M, Pichler M, Absenger G, Szkandera J, Arminger F, Schaberl-Moser R, Samonigg H, Stojakovic T, Gerger A. The preoperative lymphocyte to monocyte ratio predicts clinical outcome in patients with stage III colon cancer. Br J Cancer. 2014;110(2):435-40. https://doi.org/10.1038/bjc.2013.785.

33. Kozanhan B, Iyisoy MS. Red cell distribution width as a novel predictor of postoperative respiratory adverse events after adenotonsillectomy. Paediatr Anaesth. 2017;27(6):609-15. https:// doi.org/10.1111/pan.13138.

34. Stefaniuk P, Szymczyk A, Podhorecka M. The neutrophil to lymphocyte and lymphocyte to monocyte ratios as new prognostic factors in hematological malignancies-a narrative review. Cancer Manage Res. 2020;12:2961-77. https://doi.org/10.2147/cmar. S245928.

35. Song W, Wang K, Zhang RJ, Zou SB. Prognostic value of the lymphocyte monocyte ratio in patients with colorectal cancer: a meta-analysis. Medicine (Baltimore). 2016;95(49): e5540. https:// doi.org/10.1097/md.0000000000005540.

36. Dunn GP, Old LJ, Schreiber RD. The immunobiology of cancer immunosurveillance and immunoediting. Immunity. 2004;21(2):137-48. https://doi.org/10.1016/j.immuni.2004.07. 017.

37. Hu RJ, Ma JY, Hu G. Lymphocyte-to-monocyte ratio in pancreatic cancer: prognostic significance and meta-analysis. Clin Chim Acta. 2018;481:142-6. https://doi.org/10.1016/j.cca.2018.03.008.

38. Tham T, Olson C, Khaymovich J, Herman SW, Costantino PD. The lymphocyte-to-monocyte ratio as a prognostic indicator in head and neck cancer: a systematic review and meta-analysis. Eur Arch of Oto-rhino-laryngol. 2018;275(7):1663-70. https://doi.org/ 10.1007/s00405-018-4972-x.

39. Mano Y, Yoshizumi T, Yugawa K, Ohira M, Motomura T, Toshima T, Itoh S, Harada N, Ikegami T, Soejima Y, Maehara Y. Lymphocyte-to-monocyte ratio is a predictor of survival after liver transplantation for hepatocellular carcinoma. Liver Transpl. 2018;24(11):1603-11. https://doi.org/10.1002/lt.25204.

40. Ren H, Liu X, Wang L, Gao Y. Lymphocyte-to-monocyte ratio: a novel predictor of the prognosis of acute ischemic stroke. J Stroke Cerebrovasc Dis. 2017;26(11):2595-602. https://doi.org/ 10.1016/j.jstrokecerebrovasdis.2017.06.019.

41. Kadiyoran C, Zengin O, Cizmecioglu HA, Tufan A, Kucuksahin O, Cure MC, Cure E, Kucuk A, Ozturk MA. Monocyte to lymphocyte ratio, neutrophil to lymphocyte ratio, and red cell distribution width are the associates with gouty arthritis. Acta Medica (Hradec Kralove). 2019;62(3):99-104. https://doi.org/10.14712/18059694. 2019.132.

42. Giray D, Hallioglu O. Are there any novel markers in acute rheumatic fever: neutrophil-to-lymphocyte ratio, platelet-to-lymphocyte ratio, and monocyte-to-lymphocyte ratio. Cardiol Young. 2020;30(5):717-21. https://doi.org/10.1017/s104795112000089x. 
43. Gong S, Gao X, Xu F, Shang Z, Li S, Chen W, Yang J, Li J. Association of lymphocyte to monocyte ratio with severity of coronary artery disease. Medicine (Baltimore). 2018;97(43): e12813. https://doi.org/10.1097/md.0000000000012813.

44. Munn LL. Cancer and inflammation. Wiley Interdiscip Rev Syst Biol Med. 2017. https://doi.org/10.1002/wsbm.1370.

45. Bhatelia K, Singh K, Singh R. TLRs: linking inflammation and breast cancer. Cell Signal. 2014;26(11):2350-7. https://doi.org/ 10.1016/j.cellsig.2014.07.035.

46. Balkwill FR, Mantovani A. Cancer-related inflammation: common themes and therapeutic opportunities. Semin Cancer Biol. 2012;22(1):33-40. https://doi.org/10.1016/j.semcancer.2011.12. 005.

47. Lindholm E, Seljeflot I, Aune E, Kirkebøen KA. Proinflammatory cytokines and complement activation in salvaged blood from abdominal aortic aneurism surgery and total hip replacement surgery. Transfusion. 2012;52(8):1761-9. https://doi.org/10.1111/j. 1537-2995.2011.03528.x

48. Wang JL, Lu XY, Xu XH, Zhang KJ, Gong H, Lv D, Ni ZA, Zhu CQ. Predictive role of monocyte-to-lymphocyte ratio in patients with Klebsiella pneumonia infection: a single-center experience. Medicine (Baltimore). 2019;98(38): e17215. https://doi.org/10. 1097/md.0000000000017215.

49. Jans $\varnothing$, Jørgensen C, Kehlet H, Johansson PI. Role of preoperative anemia for risk of transfusion and postoperative morbidity in fasttrack hip and knee arthroplasty. Transfusion. 2014;54(3):717-26. https://doi.org/10.1111/trf.12332.

50. Fowler AJ, Ahmad T, Phull MK, Allard S, Gillies MA, Pearse RM. Meta-analysis of the association between preoperative anaemia and mortality after surgery. Br J Surg. 2015;102(11):1314-24. https://doi.org/10.1002/bjs.9861.

51. Lewis SR, Pritchard MW, Evans DJ, Butler AR, Alderson P, Smith AF, Roberts I. Colloids versus crystalloids for fluid resuscitation in critically ill people. Cochrane Database Syst Rev. 2018;8(8):Cd000567. https://doi.org/10.1002/14651858.CD000 567.pub7.
52. Kimbrough CW, St Hill CR, Martin RC, McMasters KM, Scoggins CR. Tumor-positive resection margins reflect an aggressive tumor biology in pancreatic cancer. J Surg Oncol. 2013;107(6):602-7. https://doi.org/10.1002/jso.23299.

53. Izzo JL Jr, Weir MR. Angiotensin-converting enzyme inhibitors. J Clin Hypertens (Greenwich). 2011;13(9):667-75. https://doi.org/ 10.1111/j.1751-7176.2011.00508.x.

54. Laudisio A, Ciaburri M, Gabrielli D, Sticchi D, Giovannini S, Bernabei R, Zuccalà G. Increased risk of bleeding in elderly patients treated with oral anticoagulants and angiotensin-converting enzyme inhibitors. Can J Cardiol. 2019;35(4):545.e3-545.e4. https://doi.org/10.1016/j.cjca.2019.02.001.

55. Kristensen KE, Zhu HJ, Wang X, Gislason GH, Torp-Pedersen C, Rasmussen HB, Markowitz JS, Hansen PR. Clopidogrel bioactivation and risk of bleeding in patients cotreated with angiotensin-converting enzyme inhibitors after myocardial infarction: a proof-of-concept study. Clin Pharmacol Ther. 2014;96(6):713-22. https://doi.org/10.1038/clpt.2014.183.

56. Malone DL, Dunne J, Tracy JK, Putnam AT, Scalea TM, Napolitano LM. Blood transfusion, independent of shock severity, is associated with worse outcome in trauma. J Trauma. 2003;54(5):898-905. https://doi.org/10.1097/01.Ta.0000060261. 10597.5c (discussion -7).

57. Dorneles Cde C, Bodanese LC, Guaragna JC, Macagnan FE, Coelho JC, Borges AP, Goldani MA, Petracco JB. The impact of blood transfusion on morbidity and mortality after cardiac surgery. Revista brasileira de cirurgia cardiovascular. 2011;26(2):222-9. https://doi.org/10.1590/s0102-76382011000200012.

Publisher's Note Springer Nature remains neutral with regard to jurisdictional claims in published maps and institutional affiliations. 